Canadian

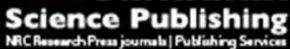

Applied Physiology, Nutrition, and Metabolism Physiologie appliquée, nutrition et métabolisme

\title{
Associations between CD36 gene polymorphisms and metabolic response to a short-term endurance training program in a young-adult population
}

\begin{tabular}{|r|l|}
\hline Journal: & Applied Physiology, Nutrition, and Metabolism \\
\hline Manuscript ID & apnm-2015-0430.R2 \\
\hline Danuscript Type: & Article \\
\hline Complete List of Authors: & $\begin{array}{r}\text { Jayewardene, Avindra; University of Sydney, Exercise Health and } \\
\text { Performance Faculty Research Group, Faculty of Health Sciences } \\
\text { Mavros, Yorgi; University of Sydney, Exercise Health and Performance } \\
\text { Faculty Research Group, Faculty of Health Sciences } \\
\text { Gwinn, Tom; University of Sydney, Exercise Health and Performance } \\
\text { Faculty Research Group, Faculty of Health Sciences } \\
\text { Hancock, Dale; University of Sydney, School of Molecular Biosciences, } \\
\text { Faculty of Science } \\
\text { Rooney, Kieron; University of Sydney, Exercise Health and Performance } \\
\text { Faculty Research Group, Faculty of Health Sciences }\end{array}$ \\
\hline Keyword: & Fatty Acid Translocase, Intervention, CVD Risk, SNPs, lipid metabolism \\
\hline & \multicolumn{2}{|c}{} \\
\hline
\end{tabular}

\section{SCHOLARONE ${ }^{\text {m }}$}

Manuscripts 
1 Associations between CD36 gene polymorphisms and metabolic response to a short-term endurance training program in a young-adult population

4 Authors:

5 Avindra F. Jayewardene ${ }^{\mathrm{a} *}$ BAppSC

6 Yorgi Mavros ${ }^{\text {a }} P h D$ (yorgi.mavros@sydney.edu.au)

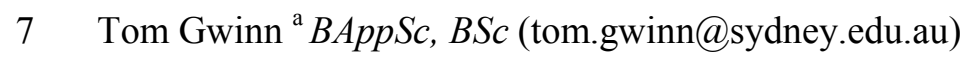

8 Dale P. Hancock ${ }^{\mathrm{b}}$ PhD (dale.hancock@sydney.edu.au)

9 Kieron B. Rooney ${ }^{\text {a }} P h D$ (kieron.rooney@sydney.edu.au)

10

11 Institutions:

$12{ }^{a}$ Exercise Health and Performance Faculty Research Group, Faculty of Health Sciences, University of

13 Sydney, Lidcombe, NSW, Australia.

$14{ }^{b}$ School of Molecular Biosciences, Faculty of Science, University of Sydney, Camperdown, NSW,

15 Australia.

16

17 Corresponding Author:

18 Avindra F. Jayewardene

19 Address: C42 - Cumberland Campus,

20 Faculty of Health Sciences,

21 The University of Sydney,

22 Lidcombe, NSW, 2141, Australia.

23 Ph: +61 29351 9403; Fax: +61 2 9351 9204; E-mail: ajay5611@uni.sydney.edu.au 


\section{Abstract}

25 Purpose: Recent studies have shown that CD36 gene variants are associated with an increased 26 prevalence of chronic disease. Although a genetic component to trainability has been proven, no data is 27 available on the influence of CD36 on training response. Methods: Two single nucleotide polymorphisms (SNPs) (rs1527479 and rs1984112) were assessed for

29 associations with whole-body substrate oxidation, response to a $75 \mathrm{~g}$ dextrose oral glucose tolerance test

30 (OGTT), fasting plasma lipids and CVD risk factors in a young healthy cohort, both using cross-sectional 31 analysis and following a 4-week endurance exercise training program. Genotyping was performed using 32 real-time polymerase chain reaction (PCR).

33 Results: Cross-sectional data was collected in 34 individuals $(22.7 \pm 3.5 \mathrm{y})$, with 17 completing the 34 training program. At baseline, TT SNP carriers at rs1527479 and wild-type (WT) GG carriers at 35 rs 1984112 were associated with significantly greater whole-body rate of fat oxidation (Fat $\left.{ }_{\mathrm{ox}}\right)$ during 36 submaximal exercise $(P<0.05)$, whilst AA carriers at the same position were associated with elevated 37 triglyceride (TG) levels. A significant genotype $x$ time interaction in Fat ${ }_{\mathrm{ox}}$ at SNP rs1984112 was 38 identified at rest. Significant genotype $\mathrm{x}$ time interactions were present at rs1527479, with TT carriers 39 exhibiting favourable response to training when compared to C-Allele carriers for fasting TG, diastolic 40 blood pressure (DBP) and mean arterial pressure (MAP).

41 Conclusion: Cross-sectional assessment identified associations with Fat ${ }_{\mathrm{ox}}$ and TG. Training response at 42 both SNPs identified "at-risk" genotypes responding favourably to the training stimulus in Fat ${ }_{\text {ox }}$, TG,

43 DBP and MAP. Although these data show potential pleiotropic influence of CD36 SNPs, assessment in a 44 larger cohort is warranted.

\section{Keywords}

47 Lipid metabolism, SNPs, Fatty Acid Translocase, Intervention, CVD Risk 
Introduction:

50 Long-chain fatty acids (LCFAs) are the predominant substrate source for ATP re-synthesis both at rest, 51 and during light to moderate exercise in healthy individuals. Fatty acid translocase (FAT)/cluster of differentiation $36(\mathrm{CD} 36)$ is a multifunctional $88 \mathrm{kDa}$ glycoprotein that has been shown to be the predominant transporter in the highly regulated process by which LCFAs are transported from adipose tissue into the heart and skeletal muscle cells, as well as the mitochondria (Ibrahimi et al. 1999; Bonen et al. 2007; Yanai et al. 2007; Nickerson et al. 2009). CD36 is unique, as it is the only identified fatty acid (FA) transport protein that modulates lipid uptake across the sarcolemma and into the mitochondria (Bezaire et al. 2006; Holloway et al. 2006; Smith et al. 2012), particularly during muscle contraction. Gene variants within the CD36 gene have previously been associated with multiple metabolic health indicators related to cardiovascular disease (CVD) (Lepretre et al. 2004; Ma et al. 2004; Febbraio and Silverstein 2007; Noel et al. 2010), highlighting a pleiotropic influence. Moreover, particular single nucleotide polymorphisms (SNPs) within the CD36 gene have also been directly associated with metabolic conditions, such as type II diabetes mellitus (T2DM), in older cohorts (Corpeleijn et al. 2006).

64 Exercise training induces an increased capacity for the uptake and oxidation of FAs (Kiens et al. 1993), 65 but the exact mechanisms by which this occurs are still to be elucidated in their entirety. The key role of 66 CD36 in the training-induced up-regulation of whole body fat oxidation (Fat ${ }_{\mathrm{ox}}$ ) has been established, via 67 both increased CD36 protein content on the plasma membrane, and elevated protein content 68 coimmunoprecipitation with carnitine palmitoyltransferase I on the mitochondrial membrane (Schenk and 69 Horowitz 2006; Talanian et al. 2010; McFarlan et al. 2012). There is evidence of considerable inter70 individual variation in the response to exercise training, with a genetic component to trainability strongly 71 supported by numerous data (Bouchard and Rankinen 2001; Bouchard 2012). We have recently published 72 the only CD36 genetic variability data in a young Australian population and identified associations 73 between SNP rs1527479 with Fat ${ }_{\text {ox }}$ during submaximal exercise, as well as between SNPs rs1527479 and 
74 rs1984112 with diastolic blood pressure (DBP) and resting heart rate (RHR) (Jayewardene et al. 2014).

75 Whilst this pilot data was limited by a small sample size and the cross-sectional nature of the study, it

76 remains undetermined whether CD36 SNPs influence individual response to an aerobic training 77 intervention, as there is no data available at present.

Individual variability in FA metabolism can be proposed to be attributable in part to polymorphisms in genes that encode membrane proteins responsible for FA transport. Prior to our previously reported pilot data (Jayewardene et al. 2014), there was only one study relating CD36 polymorphisms to FA metabolism during exercise, with their focus on CD36-deficient participants supporting the role of CD36 in LCFA mobilisation and metabolism in human participants (Yanai et al. 2007). Identification of genetic markers that have a significant influence on training response could lead to the development of individualized interventions that would allow for optimal lipid oxidation and favourable cardiometabolic response (Jeukendrup and Wallis 2005).

We conducted a prospective study to assess CD36 pleiotropic response to a supervised training intervention. We recruited a young, otherwise healthy population, similar to that in which we previously reported CD36 associated dysregulation of $\mathrm{Fat}_{\mathrm{ox}}$ during exercise. Dependent variables tested for

91 associations with CD36 genotype included $\mathrm{Fat}_{\mathrm{ox}}$, fasting plasma lipids, resting CVD risk factors and 92 response to an oral glucose tolerance test (OGTT). Focus was placed on the two SNPs (rs1527479 and 93 rs1984112) previously investigated in our cross-sectional study, which had been associated with disease 94 states in older Caucasian populations (Ma et al. 2004; Corpeleijn et al. 2006; Rodrigues et al. 2013). We 95 hypothesised that carriers of the at-risk SNP genotypes (TT carriers at rs1527479; AA carriers at 96 rs1984112) will have an attenuated response to the training program, as well as unfavourable CVD risk 97 profile when compared to the wild-type (WT) and heterozygous carriers, which could explain their 98 associations with chronic disease evident in older morbid cohorts. 
99

100

101

104

105

106

107

108

109

110

111 112 participate.

113

$114 \quad$ Stage 1 - Cross-sectional screening

115 Stage 1 consisted of two sessions. Participants reported to the laboratory on each occasion between the 116 hours of 0700 and 0900 having fasted for $\geq 10$-hrs, and having been instructed to abstain from 117 consumption of alcohol, caffeine and to refrain from strenuous exercise for the $24 \mathrm{hr}$ prior to each session.

119 Session one involved the collection of a blood sample for DNA extraction, anthropometric and body 120 composition measurements, fasting blood metabolites, an oral glucose tolerance test (OGTT) and an 121 assessment of maximal oxidative capacity $\left(\mathrm{VO}_{2 \text { peak }}\right)$.

122

34 physically active participants ( 22 males, 12 females; $22.7 \pm 0.6$ y) volunteered for the cross-sectional screening component of the study from May 2012 to December 2013. All were between 18 and 30 years old, non-smokers who were capable of performing an incremental cycling test to exhaustion. This study complied with the ethical guidelines laid down for human research by the Australian NHMRC and was approved by the University of Sydney Human Research Ethics Committee. Before taking part in the study, all participants were made aware of experimental procedures, and gave written consent to

assessment of maximal oxidative capacity ( $\mathrm{VO}_{2 \text { peak }}$ ). 
123 Session two was performed 1 - 4 weeks after session one, and involved measurement of resting CVD risk

124 factors (resting heart rate (RHR), blood pressure (BP) and rate-pressure product (RPP)) and assessment of

$125 \mathrm{Fat}_{\mathrm{ox}}$ at rest and during exercise. Brachial BP and radial RHR were measured in duplicate and in 126 accordance with consensus recommendations (Palatini et al. 2006; National Heart Foundation 2010). RPP 127 was calculated as the product of RHR and systolic BP (SBP).

Anthropometry and body composition

130 Morning fasting height (wall-mounted Holtain stadiometer; Holtain Ltd, Crymych Pembs, UK) and naked 131 weight (weight in clothes $[\mathrm{kg}]$ - weight of clothes [kg]) were measured in triplicate to the nearest $0.1 \mathrm{~cm}$ 132 and $0.1 \mathrm{~kg}$, respectively. Waist and hip circumference were measured in duplicate and in accordance with 133 consensus recommendation (Dalton et al. 2003).

135 Body fat percentage $(\% \mathrm{BF})$ was determined using bioelectrical impedance assessment (BIA) (RJL 136 Systems Inc., Clinton, MI, USA) using sex-dependent equations (Sun et al. 2003).

Fasting blood metabolites

139 Fasting blood metabolites were assessed at a similar time of the morning for all participants. Plasma 140 blood glucose was measured using fingerprick capillary samples on a glucose oxidase auto-analyser 141 (Coefficient of Variation (CV) 2.5 - 2.9\%; Accu-Chek Go, Roche Diagnostics, Basel, Switzerland). 142 Triglyceride (TG) (CV 4.3\%), total cholesterol (TC) (CV 2.3\%) and high-density lipoprotein cholesterol 143 (HDL-C) (CV 1.9\%) were measured using a CardioChek ${ }^{\circledR}$ Analyser (CardioChek ${ }^{\circledR}$, Indianna, USA).

145 Low-density lipoprotein cholesterol (LDL-C) was estimated using two separate formulae dependent on 146 fasting TG levels (Friedewald et al. 1972; Ahmadi et al. 2008). 
148

\section{Oral glucose tolerance test}

A 75-g dextrose OGTT was performed, with blood glucose (BG) measured using fingerprick capillary samples on a glucose oxidase auto-analyser (Accu-Chek Go, Roche Diagnostics, Basel, Switzerland). Samples were obtained at 0,30,60,90 and 120-min. The trapezoidal rule was used to calculate the area under the curve of glucose response (AUC).

\section{Exercise testing}

Exercise assessments were conducted on a Lode Corival cycle ergometer (Lode BV, Netherlands). Fractional percentages of $\mathrm{O}_{2}$ and $\mathrm{CO}_{2}$ were measured using a Parvo Medics TrueOne 2400 metabolic system (Parvo Medics, UT, USA). Female participants performed the assessments during the early to mid-follicular phase (Days 1 - 14) of their menstrual cycle to account for changes in circulating estradiol levels between the follicular and luteal phases which influences substrate utilisation (Wenz et al. 1997; Zderic et al. 2001).

\section{Maximal oxidative capacity $\left(\mathrm{VO}_{2 p e a k}\right)$}

A ramp protocol was utilised to assess $\mathrm{VO}_{2 \text { peak }}$, with all participants cycling at $75 \mathrm{~W}$ for the first three minutes of the assessment. Ramp test increments varied between $1 \mathrm{~W}$ per 2 - 4 seconds, determined by the assessor based on sex and following a review of participant's habitual PA levels (Baecke et al. 1982). Ventilatory gases were analysed throughout the course of the assessment, until the participant reached exhaustion. $\mathrm{VO}_{2 \text { peak }}$ was assessed using a $30 \mathrm{sec}$ average.

\section{Whole body substrate utilisation}

Participants were asked to follow a 1-day controlled diet developed based on weight $[175 \mathrm{~kJ} / \mathrm{kg} ; 4.6 \mathrm{~g}$ $\mathrm{CHO} / \mathrm{kg} ; 1.6 \mathrm{~g} \mathrm{TF} / \mathrm{kg} ; 2.5 \mathrm{~g}$ protein $/ \mathrm{kg}]$ on the day prior to this assessment in order to reduce the component of variability in substrate metabolism attributable to differences in dietary intake (Jeacocke 
173 and Burke 2010; Krishnan and Cooper 2014). A 3-day food diary was also provided to monitor dietary 174 intake and exercise patterns prior to testing. Six submaximal stages of 6 min representing $20-70 \%$ $175 \mathrm{VO}_{2 \text { peak }}$ were used to assess Fat ${ }_{\mathrm{ox}}$. Continuous ventilatory gas collection occurred using a Parvo Medics 176 TrueOne 2400 metabolic system (Parvo Medics, UT, USA), with data analysed for 2 min between 177 minutes 4 and 6 at each stage. Fat ${ }_{\mathrm{ox}}$ and whole-body rate of carbohydrate oxidation $\left(\mathrm{CHO}_{\mathrm{ox}}\right)$ were 178 calculated using non-protein respiratory quotient (RQ) (Peronnet and Massicotte 1991): Fat oxidation $\left(\right.$ g.min $\left.\min ^{-1}\right)=1.695 \cdot \mathrm{VO}_{2}-1.701 \cdot \mathrm{VCO}_{2}$ Carbohydrate oxidation $\left(\mathrm{g} \cdot \mathrm{min}^{-1}\right)=4.585 \cdot \mathrm{VCO}_{2}-3.226 \cdot \mathrm{VO}_{2}$

\section{Stage 2 - Training protocol}

183 Following the initial screening, 17 participants (13 males, 4 females; $22.7 \pm 0.7$ y) volunteered to 184 complete the endurance training intervention component of the study. The training protocol consisted of 185 three supervised submaximal cycling sessions per week for 4 weeks, each lasting 45 min. The intensity at 186 which participants trained was determined, relative to their initial $\mathrm{VO}_{2 \text { peak }}$ and increased incrementally 187 over the 4 week training period such that participants cycled at $60 \% \mathrm{VO}_{2 \text { peak }}$ for weeks 1 and $2,70 \%$ $188 \mathrm{VO}_{2 \text { peak }}$ for week 3and $75 \% \mathrm{VO}_{2 \text { peak }}$ for week 4. Participants were instructed to maintain pre-study dietary 189 and habitual PA patterns over the course of the training intervention.

\section{SNP Genotyping}

192 Genomic DNA was extracted from peripheral whole blood using a Promega wizard ${ }^{\circledR}$ genomic DNA 193 purification kit (Promega, Madison, WI, USA). Genotyping of SNP rs1527479 in the upstream promoter 194 region (intron 1B, -3489 bp relative to the translation start site), as well as SNP rs1984112 (5' flanking 195 exon 1A, -33137 bp relative to the translation start site) were performed using custom Taqman® real196 time polymerase chain reaction (PCR) technology (VIC® and FAM ${ }^{\mathrm{TM}}$ labelled-dyes). The probes were 
197 designed using the Applied Biosystems ${ }^{\circledR}$ Taqman ${ }^{\circledR}$ design tool (Applied Biosystems ${ }^{\circledR}$, Foster City, CA, 198 USA). The primer and probe sequences used for rs1527479 were as follows:

199 Forward 5'-GGGAAAAGGCCAGATAGATTCA-3'

200 Reverse 5'-ATCTGGAGAAGGGCTAATATATGCA-3'

201 Probe [VIC/FAM] 5'-AACTAGGTTGTGGCA[C/T]AG-3'

202

203 The primer and probe sequences for rs1984112 were as follows:

204 Forward 5'-TTTACTGAACAGGAAACTG-3';

205 Reverse 5'-GTAAAAATCACAGTGAAAAATT-3';

206 Probe [VIC/FAM] 5'-AGGAAACTGTAGTTA[A/G]GA-3'

The PCR reaction was performed in a total volume of $25 \mu \mathrm{L}$, containing $2.5 \mu \mathrm{L}$ of DNA template, 12.5 $\mu \mathrm{L}$ of $2 \mathrm{X}$ Applied Biosystems ${ }^{\circledR}$ Taqman ${ }^{\circledR}$ Genotyping Master mix and 1.25 $\mu \mathrm{L}$ 20X Taqman ${ }^{\circledR}$ probe mix specific for each SNP. The reactions were carried out using an Applied Biosystems ${ }^{\circledR}$ 7500FAST

211 Real-Time PCR System. The amplification consisted of initial denaturation $\left(95^{\circ} \mathrm{C}, 10 \mathrm{~min}\right) ; 40$ cycles 212 consisting of denaturation $\left(95^{\circ} \mathrm{C}, 15 \mathrm{~s}\right)$, annealing and extension $\left(60^{\circ} \mathrm{C}, 1 \mathrm{~min}\right)$.

214 Statistical Analyses

215 All data were assessed for normality using histograms and descriptive statistics. Normally distributed data 216 are presented as Mean \pm SD. Non-normally distributed data were log transformed prior to use in 217 parametric statistics if possible and presented as median (range). Both SNP loci were tested for departure 218 from Hardy - Weinberg equilibrium using a Chi-square $\left(\chi^{2}\right)$ analysis. Baseline data was analysed using 219 sequential one-way Analysis of Covariance (ANCOVA). Dominant-allele analyses were also performed 220 (SNP carriers vs. non-carriers) on baseline data and used to assess all training outcomes, due to the 221 limited sample size and adequate distribution amongst genotypes. All dependent variables were adjusted 
222 for sex, age and $\mathrm{VO}_{2 \text { peak. }}$. A split-plot repeated measures ANCOVA was used to determine time effect $\left(p_{t}\right)$

223 and genotype $\mathrm{x}$ time $\left(p_{\mathrm{gxt}}\right)$ interaction for normally distributed data. Wilcoxon signed rank test were used

224 if normalisation of data were not possible via log transformation. Training data was adjusted for 225 covariates, which included sex, age, $\mathrm{VO}_{2 \text { peak }}$ and baseline value. A value of $P<0.05$ was considered 226 statistically significant as all hypotheses were specified a priori. Post hoc analyses were considered for all 227 ANCOVA models where $P<0.1$, due to the limited sample size. Under peer-review, the suggestion was 228 made to include the alternate SNP to that being assessed as a covariate to both the one-way and repeated 229 measures ANCOVA models. The changes to the original statistical outputs are provided in the 230 supplementary material. Statistical analyses were performed using SPSS version 21.0 software (SPSS 231 Inc., Chicago, IL, USA), and bias-corrected effect sizes (Hedges' g) often used for small sample size 232 (Hedges and Olkin 2014). 


\section{Results:}

234 Participant characteristics at the first stage are presented in Table S1. Genotype distributions were in 235 Hardy-Weinberg equilibrium at both SNP loci. Three participants did not complete all baseline 236 requirements, and were excluded from analyses altogether.

239 TT carriers of rs 1527479 had significantly greater Fat ${ }_{\text {ox }}$ compared to C-Allele carriers at $40 \% \mathrm{VO}_{2 \text { peak }}(P$ $240=0.033 ; g=-0.8)$ and tended towards higher Fat ${ }_{\mathrm{ox}}$ at $60 \%(P=0.061 ; g=-0.5)$ (Figure 1 (a)). No 241 difference was observed in Fat ${ }_{\mathrm{ox}}$ during dominant model analysis of the screening data at rs $1984112(P>$ $2420.05)$ (Figure 1(c)).

At rs1527479, the TT genotype tended towards being greater at fasting blood glucose (FBG) $(P=0.066$; $g=-0.5)$ (Table 1). Genotypic variation in the cross-sectional TG screening data at rs1984112 was

246 present, with AA carriers significantly greater than G-allele carriers $(P=0.01 ; g=-0.9)$ (Table 1$)$. No 247 other significant differences were evident in OGTT and fasting plasma lipid markers at baseline $(P>$ $248 \quad 0.05$; Figure 2 (a) \& (c)).

250 No significant difference in $\mathrm{VO}_{2 \text { peak }}$ or $\mathrm{W}_{\text {peak }}$ was observed at either SNP at screening (Tables 1).

\section{Training Effect}

253 Time effect analyses are included in the supplementary material (Supplementary Table S4\& S5). Two

254 participants dropped out due to time constraints, and were assessed in the cross-sectional analyses only.

255 Excluding the two dropouts, adherence to the training intervention was $100 \%$ for all participants. No

256 adverse events were reported over the course of this study. 
258 Whole body fuel utilisation analysis at SNP rs 1984112 identified genotype $\mathrm{x}$ time interactions at rest $\left(P_{\mathrm{gxt}}\right.$ $259=0.011 ; g=-0.6)($ Figure $1(\mathrm{~d}))$, with AA carriers experiencing significantly greater increases in Fat ${ }_{\mathrm{ox}}$ 260 when compared to G-Allele carriers. No genotype $\mathrm{x}$ time interaction was observed at rs 1527479 (Figure 261 1(b)).

262

263 TT carriers of SNP rs1527479 reduced DBP $\left(P_{\mathrm{gxt}}=0.016 ; g=0.9\right)$ and MAP $\left(P_{\mathrm{gxt}}=0.028 ; g=0.8\right)$ when 264 compared to C-allele carriers (Table 2). Post-training assessment showed that TT carriers also 265 experienced a decrease in TG levels compared to C-Allele carriers $\left(P_{\mathrm{gxt}}=0.009 ; g=1.1\right)($ Table 2$)$. At 266 SNP rs1984112, a significant genotype $\mathrm{x}$ time interaction was present in HDL-C $\left(P_{\mathrm{gxt}}=0.024\right)$ (Table 3$)$. 267 No clinically relevant changes in OGTT data were present at either SNP (Figures 2 (b) \& (d)). 268

269 No training induced group-time interactions in $\mathrm{VO}_{2 \text { peak }}$ and $\mathrm{W}_{\text {peak }}$ were evident at either $\mathrm{SNP}\left(P_{\mathrm{gxt}}>0.05\right)$ 270 (Tables $2 \& 3)$.

271 


\section{Discussion:}

273 In the present study, we were able to find a number of interactions of note. Cross-sectional analysis at 274 stage 1 identified associations with our primary dependent variable, Fat ${ }_{\mathrm{ox}}$, at both SNPs. Investigation of 275 the impact of a short-term endurance-training program identified significant time effects for Fat ${ }_{\mathrm{ox}}$, along with MAP and FBG. Possible influence of CD36 gene variants on training response were also identified, 277 with genotype $\mathrm{x}$ time interactions observed in $\mathrm{Fat}_{\mathrm{ox}}$, and documented metabolic health indicators TG, 278 HDL-C, DBP and MAP. With particular emphasis on a young, healthy cohort in this functional genetic 279 study, we endeavoured to minimise secondary phenotypic influence from overt pathology commonly 280 present in older cohorts, allowing for identification of early indicators in a hypothesised "at-risk" 281 population, allowing for a better understanding of the potential confounding influence CD36 gene 282 variants.

Genetic variants within key metabolic genes could be proposed to alter either encoded protein function and/or abundance, depending on the location and influence of the SNP. This could be a possible mechanism behind the previously mentioned associations between the CD36 SNPs investigated in our research and chronic disease states and risk factors identified in older cohorts (Ma et al. 2004; Corpeleijn et al. 2006; Rodrigues et al. 2013). Whilst significant differences in Fat ${ }_{\mathrm{ox}}$ were evident during crosssectional analysis at stage 1 using both models of analysis at both SNPs, only analysis at rs1984112 was consistent with our hypothesis, with the GG WT genotype exhibiting higher Fat ${ }_{\text {ox }}$ at $20-40 \% \mathrm{VO}_{2 \text { peak }}$

291 (Supplementary Table S2).

293 When training data were analysed using the dominant model at both SNPs, a gene-exercise interaction 294 effect was only evident at rs1984112 at rest. Additional analysis performed in an attempt to possibly 295 reduce the confounding influence of the alternate SNP strengthened this association $\left(P_{\mathrm{gxt}}=0.001\right.$, 296 Supplementary Table S11). A similar analysis on SNP rs1527479 data also observed a significant 
genotype $\mathrm{x}$ time interaction at resting Fat ${ }_{\mathrm{ox}}\left(P_{\mathrm{gxt}}=0.414\right.$ to $\left.P_{\mathrm{gxt}}=0.012\right)$. Large effect sizes were also present at both SNPs $(|g|=0.6-1.1)$. Significant increases in Fat ${ }_{\text {ox }}$ were evident as a result of the training program prior to covariate adjustment, predominantly present at training specific exercise intensities (50 $70 \% \mathrm{VO}_{2 \text { peak }}$ ). With $\mathrm{CHO}_{\text {ox }}$ decreasing across all intensities at both SNPs, our data is consistent with the notion that there is a preferential switch to fat oxidation following endurance training. Research

302 investigating the ameliorating effects of exercise training on metabolic impairments, such as FA 303 accumulation, as a result of genetic factors in rat models showed that the influence of selective breeding 304 resulting in reduced expression of a number of key metabolic genes could be overturned as a result of 305 exercise-training (Lessard et al. 2011; McFarlan et al. 2012). Exercise-induced up-regulation of key 306 metabolic genes is believed to be the mechanism responsible for this result. Similar increases in proteins 307 involved in LCFA transport as a result of exercise training (FABP ${ }_{\mathrm{pm}}$, FATP1, FATP4), particularly CD36, 308 have been confirmed in numerous human models (Arkinstall et al. 2004; Roepstorff et al. 2004; Talanian et al. 2010), with a number of varying exercise modalities.

311 Cross-sectional assessment between participants in the present study observed that AA SNP carriers at 312 rs1984112 had significantly elevated TG, an association reinforced following the addition of rs1527479 313 as a covariate in ANCOVA model $(P=0.008$, Supplementary Table S10). Ma and colleagues (2004) 314 identified a haplotype, including SNP rs1984112, which was associated with not only elevated TG, but 315 also free-fatty acids (FFA) (Ma et al. 2004). With the authors suggesting their results were consistent with 316 those seen in CD36 knockout mouse models (Febbraio et al. 1999), they postulate that the increased 317 plasma FFA associated with decreased clearance, as a result of decreased CD36 expression, would lead to 318 increased hepatic FFA uptake, leading to increased production of TGs. Unfortunately, FFA was not 319 collected in the present study to test whether this hypothesis was present, but its inclusion for analysis in 320 future work would be of great interest. However, the association evident in our pre-clinical cohort is of 
321 great interest, particularly with the documented importance of TGs as a biomarker for CVD risk and all-

322 cause mortality (Miller et al. 2011; Nordestgaard and Varbo 2014).

324 Specificity in prescribing interventions aimed at reducing such CVD risk factors requires further 325 investigation. A significant gene-exercise interaction was evident in our data at rs 1527479, with the high326 risk TT genotype group exhibiting a protective reduction in TG following exercise-training when 327 compared to C-allele carriers, an interaction present independent of SNP rs1984112. Previous research 328 investigating the effect of exercise-training on TG levels suggest that in the absence of concurrent weight329 loss and/or reduced energy intake (Duncan et al. 2005; Fontana et al. 2007), there would be a minimal 330 reduction in plasma TGs, whilst elevated baseline TG level $(>1.69 \mathrm{mmol} / \mathrm{L})$ was also a determining factor 331 (Durstine et al. 2002). In the present data, baseline grouped means were below this range, participants 332 were instructed not to alter dietary patterns over the course of the intervention and no significant 333 difference in weight loss between these groups were identified. With these factors considered, the 334 genotype $\mathrm{x}$ time interactions evident could well be related to the impact of the training stimulus on CD36 335 protein function and/or abundance. Further investigation of this potential protective gene-exercise 336 interaction on plasma TG is warranted and required to make any significant and appropriate interpretation 337 of this data however, with the greater control of diet via meal provisions throughout the training 338 intervention merited, in order to ensure there would be no increase in caloric intake often associated with 339 exercise (Laan et al. 2010).

341 Whilst no significant difference in BP measures were evident in the present cross-sectional and baseline 342 data, significant genotype $\mathrm{x}$ time interactions were present at both SNP loci in our training data. Rice and 343 colleagues (2002) investigated heritability of HR and BP response to exercise training in the HERITAGE 344 family cohort (Rice et al. 2002). Following a 20-week exercise-training program, they reported that the 345 trainability of SBP in hypertensive families appears to be determined by genetic factors, this observation 
was not present in the normotensive sub-group, whilst DBP response was believed to be a result of environmental factors as opposed to genetic. In our cohort, DBP and MAP values at rs1527479 exhibited favourable adaptation for TT carriers when compared to C-allele carriers $(g=0.9$ and $g=0.8$, respectively), opposing our hypothesis that this "at-risk" group would not respond as well. DBP and MAP response when participants were stratified at rs1984112 were not expected, with an increase in DBP in both G-allele and AA groups, whilst AA carriers increased MAP and no change was seen in the G-allele group. If a genetic component of DBP and MAP trainability were to be considered, our data is consistent with the belief that the AA group would not respond as well to the training stimulus. Previous

354 assessments of genetic variance and BP response to an exercise-training program have investigated a 355 handful of genes, including ACE, ApoE, LDL and AGT genes (Hagberg et al. 1999; Rauramaa et al. 356 2002; Zhang et al. 2002). Current data suggests further examination of the influence of CD36 gene variants on BP response in a larger sample size is warranted. The role of CD36 in BP determination has been shown in spontaneous hypertensive rat (SHR) models, with a strong inverse correlation inverse correlation of renal expression of CD36 with both SBP and DBP (Pravenec et al. 2008). It is postulated that CD36 mutations may influence the regulation of BP through nitric oxide-related pathways in the

361 kidney (Zou and Cowley 1999; Pravenec et al. 2008), as CD36 is known to co-localise with endothelial 362 nitric oxide synthase (eNOS) in the caveolae of endothelial cells in the renal medulla (Bordessoule et al. 363 1993), and is a determinant of eNOS activation by FAs.

365 The variance in Fat ${ }_{\mathrm{ox}}$ identified at stage 1 analysis at both SNP loci in the present study were contrary to 366 previous cross-sectional pilot data collected by this lab in a separate study cohort (Jayewardene et al. 367 2014), where C-allele carriers at rs 1527479 shown to have elevated Fat ${ }_{\mathrm{ox}}$ when compared to TT carriers, 368 and no difference evident at SNP rs1984112 in that particular data set. As we investigated similar 369 associations in a slightly larger cohort, with the only change being a shift towards lower exercise 370 intensities, due to potential inaccuracies associated with higher exercise intensities (Jeukendrup and 
371 Wallis 2005), it may suggest that the current results are a more accurate representation of the genotypic 372 associations present within our cohort (comparisons presented in Table 4).

374 Of the significant genotype $\mathrm{x}$ time interactions identified in our stage 2 data, a number of the more 375 favourable responses to the training program were present in the "at-risk" genotypes for Fat ${ }_{\mathrm{ox}}$, TG, and 376 BP variables between both SNPs. Whilst these findings are not consistent with our hypothesis, it may 377 suggest that these particular individuals may have a greater capacity for positive metabolic flexibility 378 when an external stimuli is exerted. The implications of this theory are that the adverse associations 379 previously described at both SNPs in older, comorbid populations (Ma et al. 2004; Corpeleijn et al. 2006; 380 Rodrigues et al. 2013) are primarily a result of chronic inactivity over the course of a lifetime.

382 Although our study focuses on the role of CD36 as a transport protein in skeletal muscle during exercise, 383 Febbraio and Silverstein (2007) identified the intrinsic difficulty in investigating CD36 is that the protein 384 is expressed in multiple tissues, as well as multiple cell types within a single tissue (Febbraio and 385 Silverstein 2007). Furthermore, the lack of a non-exercise control group for the training intervention 386 means that we are unable to definitively rule out the confounding influence of external factors on 387 dependent variables included in our study.

389 Whilst a larger sample size would increase the power of this study, our preliminary data supports further 390 investigation in this study population. Additionally, broadening the scope of the study to include specific 391 dependent variables to investigate associations identified in this study would be beneficial to understand 392 possible mechanistic influences, which were beyond the scope of this particular study. Investigation of 393 genotypic influence on CD36 protein expression within the active muscle during exercise would be of 394 particular interest. 


\section{Conclusion}

397 In conclusion, cross-sectional analysis identified associations between CD36 genotype and dependent 398 variables $\mathrm{Fat}_{\mathrm{ox}}$ and TG. The training data suggests that a short-term endurance training program would be 399 sufficient to elicit significant increases in $\mathrm{Fat}_{\mathrm{ox}}$ at intensities $40-70 \%$ VO2peak. A significant genotype $\mathrm{x}$ 400 time interaction at rs1984112 in Fatox was observed, however the response was not consistent with our 401 hypothesis following training, with the "at-risk" AA SNP carriers experiencing a greater increase when 402 compared to G-Allele carriers. Training response at SNP rs1527479 was contrary to our hypothesis as 403 well, with TT SNP carriers exhibiting favourable response in fasting TG, DBP and MAP. These data may 404 suggest that these "at-risk" groups exhibit greater metabolic flexibility, allowing for preferential 405 adaptation to a training stimulus. Whilst these data show the potential pleiotropic influence of CD36 406 SNPs rs1527479 and rs1984112 on training response, further assessment in a larger cohort is warranted. 


\section{Acknowledgments}

408 The authors would like to thank Ms. Emily Medina for her assistance with data collection, and for 409 allowing us to keep it together. We also thank Ms. Diane Mould and Mr. Raymond Patton for their 410 assistance with equipment maintenance.

411

412 A. F. Jayewardene was supported by the Australian Postgraduate Award Scholarship. This study was

413 funded using the University of Sydney Faculty Funding Scheme.

414

\section{Statements}

416 Ethical approval: All procedures performed in studies involving human participants were in accordance

417 with the ethical standards of the institutional and/or national research committee and with the 1964

418 Helsinki declaration and its later amendments or comparable ethical standards.

420 Conflict of Interest: The authors declare that they have no conflict of interest. 


\section{References:}

Ahmadi, S.-A., Boroumand, M.-A., Gohari-Moghaddam, K., Tajik, P., and Dibaj, S.-M. 2008. The impact of low serum triglyceride on LDL-cholesterol estimation. Archives of Iranian Medicine 11: 31821. PMID:18426324.

Arkinstall, M.J., Bruce, C.R., Clark, S.A., Rickards, C.A., Burke, L.M., and Hawley, J.A. 2004. Regulation of fuel metabolism by preexercise muscle glycogen content and exercise intensity. Journal of Applied Physiology 97: 2275-2283. doi:10.1152/ajpendo.00557.2003.

Baecke, J.A., Burema, J., and Frijters, J.E. 1982. A short questionnaire for the measurement of habitual physical activity in epidemiological studies. American Journal of Clinical Nutrition 36: 936-42. PMID:7137077.

Bezaire, V., Bruce, C.R., Heigenhauser, G.J.F., Tandon, N.N., Glatz, J.F.C., Luiken, J. et al. 2006. Identification of fatty acid translocase on human skeletal muscle mitochondrial membranes: essential role in fatty acid oxidation. American Journal of Physiology-Endocrinology and Metabolism 290: E509-E515. doi:10.1152/ajpendo.00312.2005.

Bonen, A., Han, X.-X., Habets, D.D.J., Febbraio, M., Glatz, J.F.C., and Luiken, J.J.F.P. 2007. A null mutation in skeletal muscle FAT/CD36 reveals its essential role in insulin- and AICARstimulated fatty acid metabolism. American Journal of Physiology - Endocrinology \& Metabolism 292: E1740-9. doi:10.1152/ajpendo.00579.2006. PMID:17264223.

Bordessoule, D., Jones, M., Gatter, K.C., and Mason, D.Y. 1993. Immunohistological patterns of myeloid antigens: tissue distribution of CD13, CD14, CD16, CD31, CD36, CD65, CD66 and CD67. British Journal of Haematology 83: 370-83. doi:10.1111/j.1365-2141.1993.tb04659.x. PMID:7683483.

Bouchard, C. 2012. Genomic predictors of trainability. Experimental Physiology 97: 347-52. doi:10.1113/expphysiol.2011.058735. 21967902. 
Bouchard, C. and Rankinen, T. 2001. Individual differences in response to regular physical activity. Medicine \& Science in Sports \& Exercise 33: S446-51; discussion S452-3. PMID:11427769.

Corpeleijn, E., van der Kallen, C.J.H., Kruijshoop, M., Magagnin, M.G.P., de Bruin, T.W.A., Feskens, E.J.M. et al. 2006. Direct association of a promoter polymorphism in the CD36/FAT fatty acid transporter gene with Type 2 diabetes mellitus and insulin resistance. Diabetic Medicine 23: 90711. doi:10.1111/j.1464-5491.2006.01888.x. PMID:16911630.

Dalton, M., Cameron, A.J., Zimmet, P.Z., Shaw, J.E., Jolley, D., Dunstan, D.W. et al. 2003. Waist circumference, waist-hip ratio and body mass index and their correlation with cardiovascular disease risk factors in Australian adults. Journal of Internal Medicine 254: 555-563. doi:10.1111/j.1365-2796.2003.01229.x.

Duncan, G.E., Anton, S.D., Sydeman, S.J., Newton, R.L., Jr., Corsica, J.A., Durning, P.E. et al. 2005. Prescribing exercise at varied levels of intensity and frequency: a randomized trial. Archives of Internal Medicine 165: 2362-9. doi:10.1001/archinte.165.20.2362. PMID:16287765.

Durstine, J.L., Grandjean, P.W., Cox, C.A., and Thompson, P.D. 2002. Lipids, lipoproteins, and exercise. Journal of Cardiopulmonary Rehabilitation 22: 385-398. doi:10.1097/00008483-20021100000002. PMID: 12464825.

Febbraio, M., Abumrad, N.A., Hajjar, D.P., Sharma, K., Cheng, W., Pearce, S.F. et al. 1999. A null mutation in murine CD36 reveals an important role in fatty acid and lipoprotein metabolism. Journal of Biological Chemistry 274: 19055-62. doi:10.1074/jbc.274.27.19055. PMID:10383407.

Febbraio, M. and Silverstein, R.L. 2007. CD36: implications in cardiovascular disease. International Journal of Biochemistry \& Cell Biology 39: 2012-30. doi:10.1016/j.biocel.2007.03.012. PMID:17466567.

Fontana, L., Villareal, D.T., Weiss, E.P., Racette, S.B., Steger-May, K., Klein, S. et al. 2007. Calorie restriction or exercise: effects on coronary heart disease risk factors. A randomized, controlled 
trial. American Journal of Physiology - Endocrinology \& Metabolism 293: E197-202. doi:10.1152/ajpendo.00102.2007. PMID:17389710.

Friedewald, W.T., Levy, R.I., and Fredrickson, D.S. 1972. Estimation of the concentration of low-density lipoprotein cholesterol in plasma, without use of the preparative ultracentrifuge. Clinical Chemistry 18: 499-502. PMID:4337382.

Hagberg, J.M., Ferrell, R.E., Dengel, D.R., and Wilund, K.R. 1999. Exercise training-induced blood pressure and plasma lipid improvements in hypertensives may be genotype dependent. Hypertension 34: 18-23. doi:10.1161/01.HYP.34.1.18. PMID:10406818.

Hedges, L.V. and Olkin, I. (2014). Statistical method for meta-analysis. Academic press:

Holloway, G.P., Bezaire, V., Heigenhauser, G.J.F., Tandon, N.N., Glatz, J.F.C., Luiken, J.J.F.P. et al. 2006. Mitochondrial long chain fatty acid oxidation, fatty acid translocase/ CD36 content and carnitine palmitoyltransferase I activity in human skeletal muscle during aerobic exercise. Journal of Physiology 571: 201-210. PMID:16357012.

Ibrahimi, A., Bonen, A., Blinn, W.D., Hajri, T., Li, X., Zhong, K. et al. 1999. Muscle-specific overexpression of FAT/CD36 enhances fatty acid oxidation by contracting muscle, reduces plasma triglycerides and fatty acids, and increases plasma glucose and insulin. Journal of Biological Chemistry 274: 26761-6. doi:10.1074/jbc.274.38.26761. PMID:10480880.

Jayewardene, A.F., Gwinn, T., Hancock, D.P., Mavros, Y., and Rooney, K.B. 2014. The associations between polymorphisms in the CD36 gene, fat oxidation and cardiovascular disease risk factors in a young adult Australian population: a pilot study. Obes Res Clin Pract 8: e618-21. doi:10.1016/j.orcp.2014.09.001. PMID:25277110.

Jeacocke, N.A. and Burke, L.M. 2010. Methods to standardize dietary intake before performance testing. International Journal of Sport Nutrition \& Exercise Metabolism 20: 87-103. PMID:20479482. 
494

495

496

497

498

499

500

501

502

503

504

505

506

507

508

509

510

511

512

513

514

515

516

517

Jeukendrup, A.E. and Wallis, G.A. 2005. Measurement of substrate oxidation during exercise by means of gas exchange measurements. International Journal of Sports Medicine 26 Suppl 1: S28-37. doi:10.1055/s-2004-830512. PMID:15702454.

Kiens, B., Essengustavsson, B., Christensen, N.J., and Saltin, B. 1993. Skeletal muscle substrate utilization during submaximal exercise in man: effect of endurance training. Journal of Physiology-London 469: 459-478. doi:10.1113/jphysiol.1993.sp019823.

Krishnan, S. and Cooper, J.A. 2014. Effect of dietary fatty acid composition on substrate utilization and body weight maintenance in humans. European Journal of Nutrition 53: 691-710. doi:10.1007/s00394-013-0638-z. PMID:24363161.

Laan, D.J., Leidy, H.J., Lim, E., and Campbell, W.W. 2010. Effects and reproducibility of aerobic and resistance exercise on appetite and energy intake in young, physically active adults. Appl Physiol Nutr Metab 35: 842-7. doi:10.1139/h10-072. PMID:21164556.

Lepretre, F., Vasseur, F., Vaxillaire, M., Scherer, P.E., Ali, S., Linton, K. et al. 2004. A CD36 nonsense mutation associated with insulin resistance and familial type 2 diabetes. Human Mutation 24: 104. doi:10.1002/humu.9256. PMID:15221799.

Lessard, S.J., Rivas, D.A., Stephenson, E.J., Yaspelkis, B.B., III, Koch, L.G., Britton, S.L. et al. 2011. Exercise training reverses impaired skeletal muscle metabolism induced by artificial selection for low aerobic capacity. American Journal of Physiology-Regulatory Integrative and Comparative Physiology 300: R175-R182. doi:10.1152/ajpregu.00338.2010.

Ma, X., Bacci, S., Mlynarski, W., Gottardo, L., Soccio, T., Menzaghi, C. et al. 2004. A common haplotype at the CD36 locus is associated with high free fatty acid levels and increased cardiovascular risk in Caucasians.[Erratum appears in Hum Mol Genet. 2005 Dec 15;14(24):3973]. Human Molecular Genetics 13: 2197-205. doi:10.1093/hmg/ddh233. PMID:15282206. 
McFarlan, J.T., Yoshida, Y., Jain, S.S., Han, X.X., Snook, L.A., Lally, J. et al. 2012. In vivo, fatty acid translocase (CD36) critically regulates skeletal muscle fuel selection, exercise performance, and training-induced adaptation of fatty acid oxidation. Journal of Biological Chemistry 287: 2350223516. doi:10.1074/jbc.M111.315358. PMID:22584574.

Miller, M., Stone, N.J., Ballantyne, C., Bittner, V., Criqui, M.H., Ginsberg, H.N. et al. 2011. Triglycerides and cardiovascular disease: A scientific statement from the American Heart Association. Circulation 123: 2292-2333. doi:10.1161/CIR.0b013e3182160726. PMID:21502576.

National Heart Foundation (2010). Guide to management of hypertension 2008. http://www.heartfoundation.org.au/SiteCollectionDocuments/HypertensionGuidelines2008to2010 Update.pdf: National Heart Foundation.

Nickerson, J.G., Alkhateeb, H., Benton, C.R., Lally, J., Nickerson, J., Han, X.-X. et al. 2009. Greater transport efficiencies of the membrane fatty acid transporters FAT/CD36 and FATP4 compared with FABPpm and FATP1 and differential effects on fatty acid esterification and oxidation in rat skeletal muscle. Journal of Biological Chemistry 284: 16522-30. doi:10.1074/jbc.M109.004788. PMID:19380575.

Noel, S.E., Lai, C.-Q., Mattei, J., Parnell, L.D., Ordovas, J.M., and Tucker, K.L. 2010. Variants of the CD36 gene and metabolic syndrome in Boston Puerto Rican adults. Atherosclerosis 211: 210-5. doi:10.1016/j.atherosclerosis.2010.02.009. PMID:20223461.

Nordestgaard, B.G. and Varbo, A. 2014. Triglycerides and cardiovascular disease. Lancet 384: 626-35. doi:10.1016/S0140-6736(14)61177-6. PMID:25131982.

Palatini, P., Benetos, A., Grassi, G., Julius, S., Kjeldsen, S.E., Mancia, G. et al. 2006. Identification and management of the hypertensive patient with elevated heart rate: statement of a European Society of Hypertension Consensus Meeting. Journal of Hypertension 24: 603-10. doi:10.1097/01.hjh.0000217838.49842.1e. PMID:16531784. 
Peronnet, F. and Massicotte, D. 1991. Table of nonprotein respiratory quotient: an update. Canadian Journal of Sport Sciences 16: 23-9. PMID:1645211.

Pravenec, M., Churchill, P.C., Churchill, M.C., Viklicky, O., Kazdova, L., Aitman, T.J. et al. 2008. Identification of renal $\mathrm{Cd} 36$ as a determinant of blood pressure and risk for hypertension. Nature Genetics 40: 952-4. doi:10.1038/ng.164. PMID:18587397.

Rauramaa, R., Kuhanen, R., Lakka, T.A., Vaisanen, S.B., Halonen, P., Alen, M. et al. 2002. Physical exercise and blood pressure with reference to the angiotensinogen M235T polymorphism. Physiological Genomics 10: 71-7. doi:10.1152/physiolgenomics.00050.2002. PMID:12181364.

Rice, T., An, P., Gagnon, J., Leon, A.S., Skinner, J.S., Wilmore, J.H. et al. 2002. Heritability of HR and BP response to exercise training in the HERITAGE Family Study. Medicine \& Science in Sports \& Exercise 34: 972-9. doi:10.1097/00005768-200206000-00011. PMID:12048324.

Rodrigues, A.C., Sobrino, B., Genvigir, F.D.V., Willrich, M.A.V., Arazi, S.S., Dorea, E.L. et al. 2013. Genetic variants in genes related to lipid metabolism and atherosclerosis, dyslipidemia and atorvastatin response. Clinica Chimica Acta 417: 8-11. doi:10.1016/j.cca.2012.11.028. PMID:23247049.

Roepstorff, C., Vistisen, B., Roepstorff, K., and Kiens, B. 2004. Regulation of plasma long-chain fatty acid oxidation in relation to uptake in human skeletal muscle during exercise. American Journal of Physiology-Endocrinology and Metabolism 287: E696-E705. doi:10.1152/ajpendo.00001.2004.

Schenk, S. and Horowitz, J.F. 2006. Coimmunoprecipitation of FAT/CD36 and CPT I in skeletal muscle increases proportionally with fat oxidation after endurance exercise training. American Journal of Physiology-Endocrinology and Metabolism 291: E254-E260. doi:10.1152/ajpendo.00051.2006.

Smith, B.K., Bonen, A., and Holloway, G.P. 2012. A Dual Mechanism of Action for Skeletal Muscle FAT/CD36 During Exercise. Exercise \& Sport Sciences Reviews 40: 211-217. doi:10.1097/JES.0b013e31825eb263. PMID:22653277. 
568 Sun, S.S., Chumlea, W.C., Heymsfield, S.B., Lukaski, H.C., Schoeller, D., Friedl, K. et al. 2003.

569

570

571

572

573

574

575

576

577

578

579

580

581

582

583

584

585

586

587

588

589

590

591

592

Development of bioelectrical impedance analysis prediction equations for body composition with the use of a multicomponent model for use in epidemiologic surveys. American Journal of Clinical Nutrition 77: 331-40. PMID:12540391.

Talanian, J.L., Holloway, G.P., Snook, L.A., Heigenhauser, G.J.F., Bonen, A., and Spriet, L.L. 2010. Exercise training increases sarcolemmal and mitochondrial fatty acid transport proteins in human skeletal muscle. American Journal of Physiology - Endocrinology \& Metabolism 299: E180-8. doi:10.1152/ajpendo.00073.2010. PMID:20484014.

Wenz, M., Berend, J.Z., Lynch, N.A., Chappell, S., and Hackney, A.C. 1997. Substrate oxidation at rest and during exercise: effects of menstrual cycle phase and diet composition. Journal of Physiology \& Pharmacology 48: 851-60. PMID:9444630.

Yanai, H., Watanabe, I., Ishii, K., Morimoto, M., Fujiwara, H., Yoshida, S. et al. 2007. Attenuated aerobic exercise capacity in CD36 deficiency. Journal of Medical Genetics 44: 445-447. doi:10.1136/jmg.2007.050070.

Zderic, T.W., Coggan, A.R., and Ruby, B.C. 2001. Glucose kinetics and substrate oxidation during exercise in the follicular and luteal phases. Journal of Applied Physiology 90: 447-53. PMID:11160041.

Zhang, B., Sakai, T., Miura, S., Kiyonaga, A., Tanaka, H., Shindo, M. et al. 2002. Association of angiotensin-converting-enzyme gene polymorphism with the depressor response to mild exercise therapy in patients with mild to moderate essential hypertension. Clinical Genetics 62: 328-33. doi:10.1034/j.1399-0004.2002.620414.x. PMID:12372063.

Zou, A.P. and Cowley, A.W., Jr. 1999. Role of nitric oxide in the control of renal function and salt sensitivity. Current Hypertension Reports 1: 178-86. doi:10.1007/s11906-999-0016-7. PMID:10981063. 
593 Tables 
594 Table 1 - Stage 1 clinical characteristics of all participants according to dominant model analysis at both rs 1984112 and rs 1527479

\begin{tabular}{|c|c|c|c|c|c|c|c|c|}
\hline \multirow[t]{2}{*}{ Variable } & \multicolumn{2}{|c|}{ rs1527479 } & \multirow[t]{2}{*}{$P$} & \multirow[t]{2}{*}{$g$} & \multicolumn{2}{|c|}{ rs1984112 } & \multirow[t]{3}{*}{$P$} & \multirow[t]{3}{*}{$g$} \\
\hline & C-Allele & TT & & & G-Allele & $\mathbf{A A}$ & & \\
\hline$n$ & 24 & 10 & & & 21 & 13 & & \\
\hline \multicolumn{9}{|c|}{ Anthropometric measures } \\
\hline Age (yrs) & $22.6 \pm 3.6$ & $22.7 \pm 3.4$ & 0.955 & - & $22.0 \pm 3.2$ & $23.8 \pm 3.7$ & 0.14 & - \\
\hline Height (cm) & $175.3 \pm 10.1$ & $168.7 \pm 7.0$ & 0.011 & - & $173.0 \pm 10.8$ & $174.0 \pm 8.0$ & 0.55 & - \\
\hline Weight (kg) & $69.5(46.4)$ & $72.8(24.9)$ & 0.11 & 0.3 & $70.5(39.7)$ & $71.9(32.6)$ & 0.244 & -0.4 \\
\hline BMI $\left(\mathrm{kg} \cdot \mathrm{m}^{-2}\right)$ & $23.4 \pm 2.7$ & $23.9 \pm 2.1$ & 0.511 & -0.2 & $23.5(9.3)$ & $23.2(7.9)$ & 0.33 & -0.5 \\
\hline$\%$ Body fat & $20.1 \pm 8.0$ & $21.4 \pm 5.7$ & 0.228 & -0.2 & $18.1(21.8)$ & $23.0(26.9)$ & 0.124 & -0.2 \\
\hline WC (cm) & $78.0 \pm 6.7$ & $78.2 \pm 6.2$ & 0.98 & 0.0 & $76.3(18.0)$ & $75.4(25.7)$ & 0.72 & -0.4 \\
\hline $\mathrm{HC}(\mathrm{cm})$ & $98.0 \pm 5.3$ & $96.2 \pm 6.1$ & 0.402 & 0.3 & $96.6 \pm 5.6$ & $98.9 \pm 5.3$ & 0.433 & -0.4 \\
\hline WHR & $0.80 \pm 0.04$ & $0.81 \pm 0.05$ & 0.284 & -0.2 & $0.80 \pm 0.04$ & $0.80 \pm 0.05$ & 0.743 & 0.0 \\
\hline SBP (mmHg) & $114 \pm 10$ & $120 \pm 7$ & 0.1 & -0.6 & $116 \pm 8$ & $114 \pm 11$ & 0.806 & 0.2 \\
\hline DBP (mmHg) & $72 \pm 6$ & $72 \pm 9$ & 0.673 & 0.0 & $72 \pm 7$ & $72 \pm 6$ & 0.741 & 0.0 \\
\hline MAP (mmHg) & $86 \pm 6$ & $88 \pm 7$ & 0.664 & -0.3 & $87 \pm 6$ & $86 \pm 7$ & 0.885 & 0.2 \\
\hline RHR (bpm) & $53 \pm 9$ & $55 \pm 8$ & 0.447 & -0.2 & $56 \pm 9$ & $50 \pm 8$ & 0.139 & 0.7 \\
\hline RPP (mmHg.bpm) & $6072 \pm 1269$ & $6585 \pm 860$ & 0.237 & -0.4 & $6504 \pm 1135$ & $5770 \pm 1135$ & 0.203 & 0.6 \\
\hline \multicolumn{9}{|l|}{ Fasting Plasma ${ }^{a}$} \\
\hline TC $\left(\mathrm{mmol}^{-\mathrm{L}^{-1}}\right)$ & $3.98 \pm 0.63$ & $3.81 \pm 0.66$ & 0.571 & 0.3 & $3.87 \pm 0.64$ & $4.02 \pm 0.63$ & 0.993 & -0.2 \\
\hline HDL-C (mmol.L $\left.{ }^{-1}\right)$ & $1.36 \pm 0.30$ & $1.29 \pm 0.44$ & 0.727 & 0.2 & $1.35 \pm 0.32$ & $1.32 \pm 0.40$ & 0.351 & 0.1 \\
\hline LDL-C (mmol.L $\left.{ }^{-1}\right)$ & $2.08 \pm 0.55$ & $2.00 \pm 0.40$ & 0.69 & 0.2 & $1.96 \pm 0.45$ & $2.22 \pm 0.56$ & 0.347 & -0.5 \\
\hline TG (mmol.L $\left.{ }^{-1}\right)$ & $0.80 \pm 0.18$ & $0.80 \pm 0.19$ & 0.849 & 0.0 & $0.73(0.59)$ & $0.82(0.67)$ & 0.01 & -0.9 \\
\hline \multicolumn{9}{|c|}{ Oral glucose tolerance test (OGTT) } \\
\hline $\mathrm{BG}_{0}\left(\mathrm{mmol}^{-\mathrm{L}^{-1}}\right)$ & $4.9 \pm 0.4$ & $5.1 \pm 0.3$ & 0.066 & -0.5 & $5.0 \pm 0.4$ & $4.9 \pm 0.4$ & 0.182 & 0.2 \\
\hline
\end{tabular}




\begin{tabular}{|c|c|c|c|c|c|c|c|c|}
\hline $\mathrm{BG}_{120}\left(\mathrm{mmol} \cdot \mathrm{L}^{-1}\right)$ & $6.0 \pm 1.0$ & $5.8 \pm 1.0$ & 0.634 & 0.2 & $6.1 \pm 1.0$ & $5.6 \pm 0.9$ & 0.353 & 0.5 \\
\hline 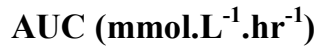 & $14.2 \pm 1.5$ & $13.5 \pm 2.2$ & 0.282 & 0.4 & $14.0 \pm 1.9$ & $14.0 \pm 1.5$ & 0.854 & 0.0 \\
\hline \multicolumn{9}{|l|}{ Exercise variables } \\
\hline$V_{2} O_{2 \text { peak }}\left(L \cdot \min ^{-1}\right)$ & $3.1 \pm 0.6$ & $3.1 \pm 0.8$ & 0.95 & 0.0 & $3.0 \pm 0.7$ & $3.2 \pm 0.7$ & 0.362 & -0.3 \\
\hline $\mathbf{W}_{\text {peak }}$ (Watts) & $258(221)$ & 271(229) & 0.978 & -0.1 & $258 \pm 65$ & $269 \pm 64$ & 0.996 & -0.2 \\
\hline
\end{tabular}

Note: Data presented as means \pm SDs. Non-normally distributed data presented as median (range). BMI, body mass index; WC, waist

596 circumference; HC, hip circumference; WHR, waist-to-hip ratio; SBP, systolic blood pressure; DBP, diastolic blood pressure; MAP, mean arterial

597 pressure; RHR, resting heart rate; RPP, rate-pressure product; TC, total cholesterol; HDL-C, high-density lipoprotein cholesterol; LDL-C, low-

598 density lipoprotein cholesterol; TG, triglyceride; FBG, fasting blood glucose; $\mathrm{BG}_{120}$, blood glucose at 120 -min of the OGTT; VO 2 peak, peak

599 oxidative capacity; $\mathrm{W}_{\text {peak }}$, peak power output; Fat ${ }_{\mathrm{ox} 0}$, whole body fat oxidation rate at rest. ${ }^{\mathrm{a}}$ Metabolite readings outside the range of the

600 CardioChek ${ }^{\circledR}$ analyser were entered as the closest limit value for the respective assay. 
601 Table 2 - Training-induced adaptations of dependent variables for dominant model analysis at rs 1527479.

\begin{tabular}{|c|c|c|c|c|c|}
\hline $\begin{array}{l}\text { Variable } \\
n\end{array}$ & $\begin{array}{c}\text { C-Allele } \\
11\end{array}$ & $\begin{array}{c}\text { TT } \\
6\end{array}$ & $\begin{array}{c}\text { Mean Difference } \\
(95 \% \mathrm{CI})\end{array}$ & $P_{\text {gxt }}$ & $g$ \\
\hline \multicolumn{6}{|l|}{ Anthropometric measures } \\
\hline \multicolumn{6}{|l|}{ Weight (kg) } \\
\hline Baseline & $76.2 \pm 12.7$ & $69.1 \pm 10.0$ & & & \\
\hline Response & $0.4 \pm 2.3$ & $-1.4 \pm 2.3$ & $-1.8(-11.1,14.6)$ & 0.233 & -0.1 \\
\hline \multicolumn{6}{|l|}{ BMI $\left(\mathrm{kg} \cdot \mathrm{m}^{-2}\right)$} \\
\hline Baseline & $24.0 \pm 3.2$ & $23.6 \pm 2.1$ & & & \\
\hline Response & $0.1 \pm 0.7$ & $-0.5 \pm 0.8$ & $0.6(-2.6,3.7)$ & 0.164 & -0.1 \\
\hline \multicolumn{6}{|l|}{$\%$ Body fat } \\
\hline Baseline & $18.3 \pm 8.4$ & $21.0 \pm 4.6$ & & & \\
\hline Response & $0.6 \pm 1.8$ & $-0.1 \pm 3.9$ & $0.7(-7.2,8.6)$ & 0.69 & 0.1 \\
\hline \multicolumn{6}{|l|}{ WC (cm) } \\
\hline Baseline & $80.8 \pm 8.2$ & $77.8 \pm 7.7$ & & & \\
\hline Response & $0.0 \pm 2.7$ & $-1.8 \pm 2.5$ & $1.8(-6.8,10.6)$ & 0.279 & 0.2 \\
\hline \multicolumn{6}{|l|}{$\mathrm{HC}(\mathrm{cm})$} \\
\hline Baseline & $99.0 \pm 6.5$ & $96.3 \pm 4.0$ & & & \\
\hline Response & $-1.0 \pm 3.2$ & $-1.4 \pm 2.9$ & $0.4(-5.8,6.6)$ & 0.616 & 0.1 \\
\hline \multicolumn{6}{|l|}{ WHR } \\
\hline Baseline & $0.82 \pm 0.03$ & $0.82 \pm 0.06$ & & & \\
\hline Response & $0.01 \pm 0.03$ & $-0.01 \pm 0.01$ & $0.02(-0.03,0.06)$ & 0.346 & 0.4 \\
\hline \multicolumn{6}{|l|}{ SBP (mmHg) } \\
\hline Baseline & $120 \pm 7$ & $120 \pm 6$ & & & \\
\hline Response & $-1 \pm 5$ & $-2 \pm 7$ & $1(-6,8)$ & 0.625 & 0.1 \\
\hline \multicolumn{6}{|l|}{ DBP (mmHg) } \\
\hline Baseline & $74 \pm 7$ & $74 \pm 8$ & & & \\
\hline Response & $4 \pm 9$ & $-3 \pm 6$ & $7(-1,15)$ & 0.016 & 0.9 \\
\hline \multicolumn{6}{|l|}{ MAP (mmHg) } \\
\hline Baseline & $89 \pm 5$ & $90 \pm 7$ & & & \\
\hline Response & $3 \pm 6$ & $-3 \pm 6$ & $6(-1,11)$ & 0.028 & 0.8 \\
\hline \multicolumn{6}{|l|}{ RHR (bpm) } \\
\hline Baseline & $54 \pm 7$ & $56 \pm 9$ & & & \\
\hline Response & $-2 \pm 5$ & $-2 \pm 8$ & $0(-8,9)$ & 0.954 & 0.1 \\
\hline RPP (mmHg.bpm) & & & & & \\
\hline
\end{tabular}




\begin{tabular}{|c|c|c|c|c|c|}
\hline $\begin{array}{l}\text { Baseline } \\
\text { Response }\end{array}$ & $\begin{array}{l}6549 \pm 964 \\
-265 \pm 718\end{array}$ & $\begin{array}{c}6710 \pm 927 \\
-362 \pm 1022\end{array}$ & $106(-932,1127)$ & 0.959 & 0.1 \\
\hline \multicolumn{6}{|l|}{ Fasting plasma ${ }^{a}$} \\
\hline \multicolumn{6}{|l|}{ TC (mmol.L $\left.{ }^{-1}\right)$} \\
\hline Baseline & $3.98 \pm 0.70$ & $3.83 \pm 0.76$ & & & \\
\hline Response & $-0.39 \pm 0.50$ & $-0.04 \pm 0.59$ & $-0.35(-1.14,0.43)$ & 0.394 & -0.5 \\
\hline \multicolumn{6}{|l|}{ HDL-C (mmol.L $\left.{ }^{-1}\right)$} \\
\hline Baseline & $1.24 \pm 0.23$ & $1.35 \pm 0.57$ & & & \\
\hline Response & $-0.06 \pm 0.09$ & $0.02 \pm 0.28$ & $-0.08(-0.48,0.34)$ & 0.22 & -0.2 \\
\hline \multicolumn{6}{|l|}{ LDL-C (mmol.L $\left.{ }^{-1}\right)$} \\
\hline Baseline & $2.22 \pm 0.72$ & $2.00 \pm 0.49$ & & & \\
\hline Response & $-0.28 \pm 0.58$ & $-0.05 \pm 0.76$ & $-0.23(-0.95,0.47)$ & 0.725 & -0.3 \\
\hline \multicolumn{6}{|l|}{ TG $\left(\mathrm{mmol}^{-1} \mathrm{~L}^{-1}\right)$} \\
\hline Baseline & $0.86 \pm 0.23$ & $0.84 \pm 0.21$ & & & \\
\hline Response & $0.17 \pm 0.24$ & $-0.08 \pm 0.17$ & $0.25(0.01,0.49)$ & 0.009 & 1.1 \\
\hline \multicolumn{6}{|c|}{ Oral glucose tolerance test (OGTT) } \\
\hline \multicolumn{6}{|l|}{$\mathrm{BG}_{0}\left(\mathrm{mmol} \mathrm{L}^{-1}\right)$} \\
\hline Baseline & $4.8 \pm 0.4$ & $5.1 \pm 0.3$ & & & \\
\hline Response & $0.2 \pm 0.6$ & $-0.3 \pm 0.5$ & $0.5(0.0,0.9)$ & 0.807 & 1.1 \\
\hline \multicolumn{6}{|l|}{$\mathrm{BG}_{120}\left(\mathrm{mmol} . \mathrm{L}^{-1}\right)$} \\
\hline Baseline & $6.0 \pm 0.9$ & $5.9 \pm 0.5$ & & & \\
\hline Response & $-0.4 \pm 1.0$ & $-0.1 \pm 1.1$ & $-0.3(-1.2,0.5)$ & 0.682 & -0.4 \\
\hline \multicolumn{6}{|l|}{ 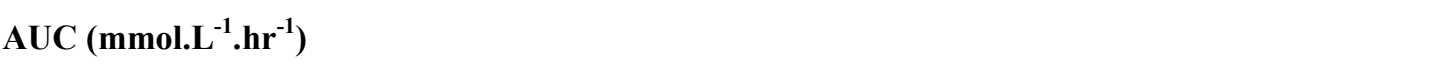 } \\
\hline Baseline & $14.2 \pm 1.3$ & $13.6 \pm 1.2$ & & & \\
\hline Response & $0.2 \pm 1.1$ & $0.2 \pm 1.0$ & $0.0(-1.3,1.4)$ & 0.567 & 0.0 \\
\hline \multicolumn{6}{|l|}{ Exercise Variables } \\
\hline \multicolumn{6}{|l|}{$\mathrm{VO}_{2 \text { peak }}\left(\mathrm{L} \cdot \mathrm{min}^{-1}\right)$} \\
\hline Baseline & $3.2 \pm 0.6$ & $3.1 \pm 0.8$ & & & \\
\hline Response & $0.2 \pm 0.3$ & $0.1 \pm 0.2$ & $0.1(-0.6,0.9)$ & 0.149 & 0.2 \\
\hline \multicolumn{6}{|l|}{$W_{\text {peak }}$ (Watts) } \\
\hline Baseline & $272 \pm 60$ & $259 \pm 69$ & & & \\
\hline Response & $28 \pm 19$ & $21 \pm 13$ & $7(-61,75)$ & 0.459 & 0.1 \\
\hline
\end{tabular}

602 Note: Data presented as means \pm SDs. Non-normally distributed data presented as median (range). BMI,

603 body mass index; WC, waist circumference; HC, hip circumference; WHR, waist-to-hip ratio; SBP, 604 systolic blood pressure; DBP, diastolic blood pressure; MAP, mean arterial pressure; RHR, resting heart 
605 rate; RPP, rate-pressure product; TC, total cholesterol; HDL-C, high-density lipoprotein cholesterol;

606 LDL-C, low-density lipoprotein cholesterol; TG, triglyceride; BG, blood glucose; $\mathrm{BG}_{\mathrm{Xx}}$, blood glucose at $607 \mathrm{XX}$ min of the OGTT; $\mathrm{VO}_{2 \text { peak }}$, peak oxidative capacity; $\mathrm{W}_{\text {peak }}$, peak power output. ${ }^{\mathrm{a}}$ Metabolite readings 608 outside the range of the CardioChek ${ }^{\circledR}$ analyser were entered as the closest limit value for the respective 609 assay. Adjustment was for age, sex, $\mathrm{VO}_{2 \text { peak }}$ and baseline reading of the corresponding dependent 610 variable.

611 
612 Table 3 - Training-induced adaptations of dependent variables for dominant model analysis at rs 1984112.

\begin{tabular}{|c|c|c|c|c|c|c|}
\hline $\begin{array}{l}\text { Variable } \\
n\end{array}$ & & $\begin{array}{c}\text { G-Allele } \\
11\end{array}$ & $\begin{array}{c}\mathbf{A A} \\
6\end{array}$ & $\begin{array}{c}\text { Mean Difference } \\
(95 \% \mathrm{CI})\end{array}$ & $P_{\mathrm{gxt}}$ & $g$ \\
\hline \multicolumn{7}{|c|}{ Anthropometric measures } \\
\hline \multicolumn{7}{|c|}{ Weight (kg) } \\
\hline & Baseline & $69.7 \pm 12$ & $80.9 \pm 8$ & & & \\
\hline & Response & $-0.1 \pm 2.9$ & $-0.3 \pm 1.2$ & $0.2(-11.8,12.1)$ & 0.823 & 0.4 \\
\hline \multicolumn{7}{|c|}{ BMI $\left(\mathrm{kg} \cdot \mathrm{m}^{-2}\right)$} \\
\hline & Baseline & $22.7 \pm 2.0$ & $26.0 \pm 3.0$ & & & \\
\hline & Response & $-0.1 \pm 0.9$ & $-0.1 \pm 0.4$ & $0.0(-2.6,2.6)$ & 0.693 & 0.0 \\
\hline \multicolumn{7}{|c|}{$\%$ Body fat } \\
\hline & Baseline & $18.3 \pm 4.8$ & $21.1 \pm 10.7$ & & & \\
\hline & Response & $-0.1 \pm 2.7$ & $1.2 \pm 2.5$ & $-1.3(-9.2,6.6)$ & 0.461 & -0.2 \\
\hline \multicolumn{7}{|l|}{ WC (cm) } \\
\hline & Baseline & $77.1 \pm 6.2$ & $84.7 \pm 8.9$ & & & \\
\hline & Response & $-1.0 \pm 2.8$ & $0.1 \pm 2.5$ & $-1.1(-8.9,6.7)$ & 0.56 & -0.2 \\
\hline \multicolumn{7}{|l|}{$\mathrm{HC}(\mathrm{cm})$} \\
\hline & Baseline & $96.2 \pm 5.0$ & $95.0 \pm 5.9$ & & & \\
\hline & Response & $-1.2 \pm 3.7$ & $-1.1 \pm 1.4$ & $-0.1(-5.8,5.6)$ & 0.993 & 0.0 \\
\hline \multicolumn{7}{|l|}{ WHR } \\
\hline & Baseline & $0.80 \pm 0.04$ & $0.83 \pm 0.05$ & & & \\
\hline & Response & $-0.00 \pm 0.03$ & $0.01 \pm 0.02$ & $-0.01(-0.05,0.04)$ & 0.366 & -0.2 \\
\hline \multicolumn{7}{|c|}{ SBP (mmHg) } \\
\hline & Baseline & $119 \pm 6$ & $122 \pm 6$ & & & \\
\hline & Response & $-1 \pm 6$ & $-2 \pm 5$ & $1(-6,7)$ & 0.72 & 0.1 \\
\hline \multicolumn{7}{|c|}{ DBP (mmHg) } \\
\hline & Baseline & $74 \pm 7$ & $75 \pm 8$ & & & \\
\hline & Response & $1 \pm 8$ & $3 \pm 11$ & $-2(-10,6)$ & 0.444 & -0.3 \\
\hline \multicolumn{7}{|c|}{ MAP (mmHg) } \\
\hline & Baseline & $89 \pm 6$ & $90 \pm 6$ & & & \\
\hline & Response & $0 \pm 6$ & $2 \pm 7$ & $-2(-8,5)$ & 0.559 & -0.2 \\
\hline \multicolumn{7}{|c|}{ RHR (bpm) } \\
\hline & Baseline & $58 \pm 6$ & $49 \pm 6^{*}$ & & & \\
\hline & Response & $-1 \pm 6$ & $-3 \pm 6$ & $2(-5,8)$ & 0.365 & 0.2 \\
\hline
\end{tabular}




\begin{tabular}{|c|c|c|c|c|c|c|}
\hline & Baseline & $6922 \pm 802$ & $6026 \pm 910$ & & & \\
\hline & Response & $-224 \pm 873$ & $-436 \pm 724$ & $212(-696,1120)$ & 0.278 & 0.2 \\
\hline \multicolumn{7}{|l|}{ Fasting plasma $^{a}$} \\
\hline \multicolumn{7}{|l|}{ TC $\left(m m o l . L^{-1}\right)$} \\
\hline & Baseline & $3.86 \pm 0.72$ & $4.05 \pm 0.72$ & & & \\
\hline & Response & $-0.17 \pm 0.49$ & $-0.46 \pm 0.63$ & $0.29(-0.49,1.07)$ & 0.208 & 0.4 \\
\hline \multicolumn{7}{|c|}{ HDL-C (mmol.. $\left.{ }^{-1}\right)$} \\
\hline & Baseline & $1.38 \pm 0.38$ & $1.09 \pm 0.31$ & & & \\
\hline & Response & $-0.03 \pm 0.21$ & $-0.03 \pm 0.11$ & $0.00(-0.39,0.38)$ & 0.024 & 0.0 \\
\hline \multicolumn{7}{|c|}{ LDL-C (mmol.L $\left.\mathbf{L}^{-1}\right)$} \\
\hline & Baseline & $1.96 \pm 0.58$ & $2.48 \pm 0.68$ & & & \\
\hline & Response & $-0.08 \pm 0.55$ & $-0.42 \pm 0.78$ & $0.34(-0.32,1.01)$ & 0.636 & 0.5 \\
\hline \multicolumn{7}{|l|}{ TG $\left(\mathbf{m m o l .} \mathbf{L}^{-1}\right)$} \\
\hline & Baseline & $0.77 \pm 0.15$ & $1.00 \pm 0.25 \dagger$ & & & \\
\hline & Response & $0.03 \pm 0.21$ & $0.18 \pm 0.28$ & $-0.15(-0.36,0.05)$ & 0.336 & -0.8 \\
\hline \multicolumn{7}{|c|}{ Oral glucose tolerance test (OGTT) } \\
\hline \multicolumn{7}{|l|}{$\mathrm{BG}_{0}\left(\mathrm{mmol}^{-\mathrm{L}^{-1}}\right)$} \\
\hline & Baseline & $4.8 \pm 0.5$ & $5.0 \pm 0.3$ & & & \\
\hline & Response & $-0.0 \pm 0.6$ & $0.1 \pm 0.6$ & $-0.1(-0.6,0.3)$ & 0.646 & -0.3 \\
\hline \multicolumn{7}{|l|}{$\mathrm{BG}_{120}\left(\mathrm{mmol} . \mathrm{L}^{-1}\right)$} \\
\hline & Baseline & $6.2 \pm 0.8$ & $5.4 \pm 0.5$ & & & \\
\hline & Response & $-0.2 \pm 1.1$ & $-0.4 \pm 0.9$ & $0.2(-0.6,1.0)$ & 0.423 & 0.3 \\
\hline \multicolumn{7}{|c|}{$\operatorname{AUC}\left(\mathbf{m m o l} . \mathrm{L}^{-1} \cdot \mathrm{hr}^{-1}\right)$} \\
\hline & Baseline & $13.7 \pm 1.1$ & $14.6 \pm 1.5$ & & & \\
\hline & Response & $0.0 \pm 1.0$ & $0.5 \pm 1.1$ & $-0.5(-1.8,0.8)$ & 0.261 & -0.4 \\
\hline \multicolumn{7}{|c|}{ Exercise Variables } \\
\hline \multicolumn{7}{|l|}{$V O_{2 \text { peak }}\left(L \cdot \min ^{-1}\right)$} \\
\hline & Baseline & $3.0 \pm 0.8$ & $3.4 \pm 0.4$ & & & \\
\hline & Response & $0.2 \pm 0.2$ & $0.2 \pm 0.3$ & $0.0(-0.7,0.7)$ & 0.862 & 0.0 \\
\hline \multicolumn{7}{|l|}{$W_{\text {peak }}$ (Watts) } \\
\hline & Baseline & $253 \pm 68$ & $294 \pm 40$ & & & \\
\hline & Response & $26 \pm 19$ & $23 \pm 15$ & $3(-62,68)$ & 0.951 & 0.1 \\
\hline
\end{tabular}

613 Note: Data presented as means \pm SDs. Non-normally distributed data presented as median (range). $* P=$

$6140.027 ; \uparrow P=0.029$, BMI, body mass index; WC, waist circumference; HC, hip circumference; WHR, 615 waist-to-hip ratio; SBP, systolic blood pressure; DBP, diastolic blood pressure; MAP, mean arterial 
616 pressure; RHR, resting heart rate; RPP, rate-pressure product; TC, total cholesterol; HDL-C, high-density

617 lipoprotein cholesterol; LDL-C, low-density lipoprotein cholesterol; TG, triglyceride; BG, blood glucose;

$618 \mathrm{BG}_{\mathrm{XX}}$, blood glucose at XX min of the OGTT; $\mathrm{VO}_{2 \text { peak, }}$, peak oxidative capacity; $\mathrm{W}_{\text {peak, }}$ peak power

619 output. ${ }^{a}$ Metabolite readings outside the range of the CardioChek $®$ analyser were entered as the closest

620 limit value for the respective assay. Adjustment was for age, sex, $\mathrm{VO}_{2 \text { peak }}$ and baseline reading of the

621 corresponding dependent variable.

622 
623 Table 4 - Summary of significant cross-sectional associations between SNPs rs1527479 and rs1984112 in

624 a young-adult Australian cohort to date - similarities and differences from a previous data in an identically 625 recruited cohort.

\begin{tabular}{|c|c|}
\hline Current Study $(\mathrm{N}=34)$ & Jayewardene et al. (2014) $(\mathrm{N}=22)$ \\
\hline \multicolumn{2}{|l|}{$r s 1984112$} \\
\hline 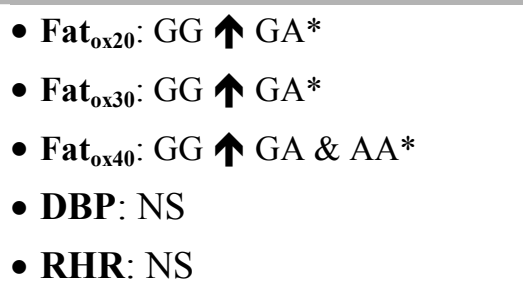 & 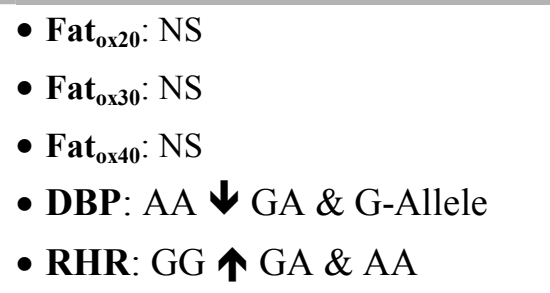 \\
\hline \multicolumn{2}{|l|}{ rs1527479 } \\
\hline $\begin{array}{l}\text { - } \text { Fat }_{\mathbf{0 x 4 0}} \text { : TT } \boldsymbol{\uparrow} \text {-allele \& CT* } \\
\text { - RHR: NS } \\
\text { - RPP: TT tended } \uparrow \text { CC \& CT* }\end{array}$ & $\begin{array}{l}\text { - } \text { Fat }_{\mathbf{0 x 4 0}}: \text { TT } \downarrow \text { CC } \\
\text { - RHR: TT } \uparrow \text { C-allele } \\
\text { - RPP: TT } \uparrow \text { C-allele }\end{array}$ \\
\hline
\end{tabular}

626 Note: DBP, diastolic blood pressure; Fat ${ }_{\mathrm{oxXx}}$, whole body fat oxidation rate at $\mathrm{XX} \% \mathrm{VO}_{2 \text { peak }}$; NS, not

627 significant; RHR, resting heart rate; RPP, rate-pressure product. *Genotypic analysis included in the 628 supplementary material. 


\section{Figure Captions}

630 Fig. 1 Whole body rate of fat oxidation (Fat ${ }_{\mathrm{ox}}$ ) data stratified by dominant-allele model analysis; (a) Stage 6311 cross-sectional absolute data for C-Allele $(\mathrm{n}=24)$ and TT carriers $(\mathrm{n}=10)$ at $\mathrm{rs} 1527479, * P<0.05$; (b) 632 Change $(\Delta)$ data following training intervention stratified at C-Allele $(\mathrm{n}=11)$ and TT carriers $(\mathrm{n}=6)$ at 633 rs1527479; (c) Stage 1 cross-sectional absolute data for G-Allele $(\mathrm{n}=21)$ and AA carriers $(\mathrm{n}=13)$ at 634 rs1984112; (d) Change $(\Delta)$ data following training intervention stratified at G-Allele $(\mathrm{n}=11)$ and AA 635 carriers $(\mathrm{n}=6)$ at $\mathrm{rs} 1984112, * * P_{\mathrm{gxt}}<0.05$. Data presented as means \pm SD. Non-normally distributed data 636 presented as median (range). Fat ${ }_{\mathrm{ox} 0}$, whole body fat oxidation rate at rest; Fat ${ }_{\mathrm{oxXx}}$, whole body fat 637 oxidation rate at $\mathrm{XX} \% \mathrm{VO}_{2 \text { peak }}$. Adjustment was for age, sex, $\mathrm{VO}_{2 \text { peak }}$ and baseline reading of the 638 corresponding dependent variable

640 Fig. 2 Oral glucose tolerance (OGTT) data stratified by dominant-allele model analysis; (a) Stage 1 cross641 sectional absolute data for C-Allele $(\mathrm{n}=24)$ and TT carriers $(\mathrm{n}=10)$ at $\mathrm{rs} 1527479, * P<0.05$; (b) Change $642(\Delta)$ data following training intervention stratified at in C-Allele $(\mathrm{n}=11)$ and TT carriers $(\mathrm{n}=6)$ at 643 rs1527479; (c) Stage 1 cross-sectional absolute data for G-Allele $(n=21)$ and AA carriers $(n=13)$ at 644 rs1984112; (d) Change $(\Delta)$ data following training intervention stratified at G-Allele $(\mathrm{n}=11)$ and AA 645 carriers $(\mathrm{n}=6)$ at $\mathrm{rs} 1984112, * * P_{\mathrm{gxt}}<0.05$. Data presented as means $\pm \mathrm{SD}$. Non-normally distributed data 646 presented as median (range). Adjustment was for age, sex, $\mathrm{VO}_{2 \text { peak }}$ and baseline reading of the 647 corresponding dependent variable 

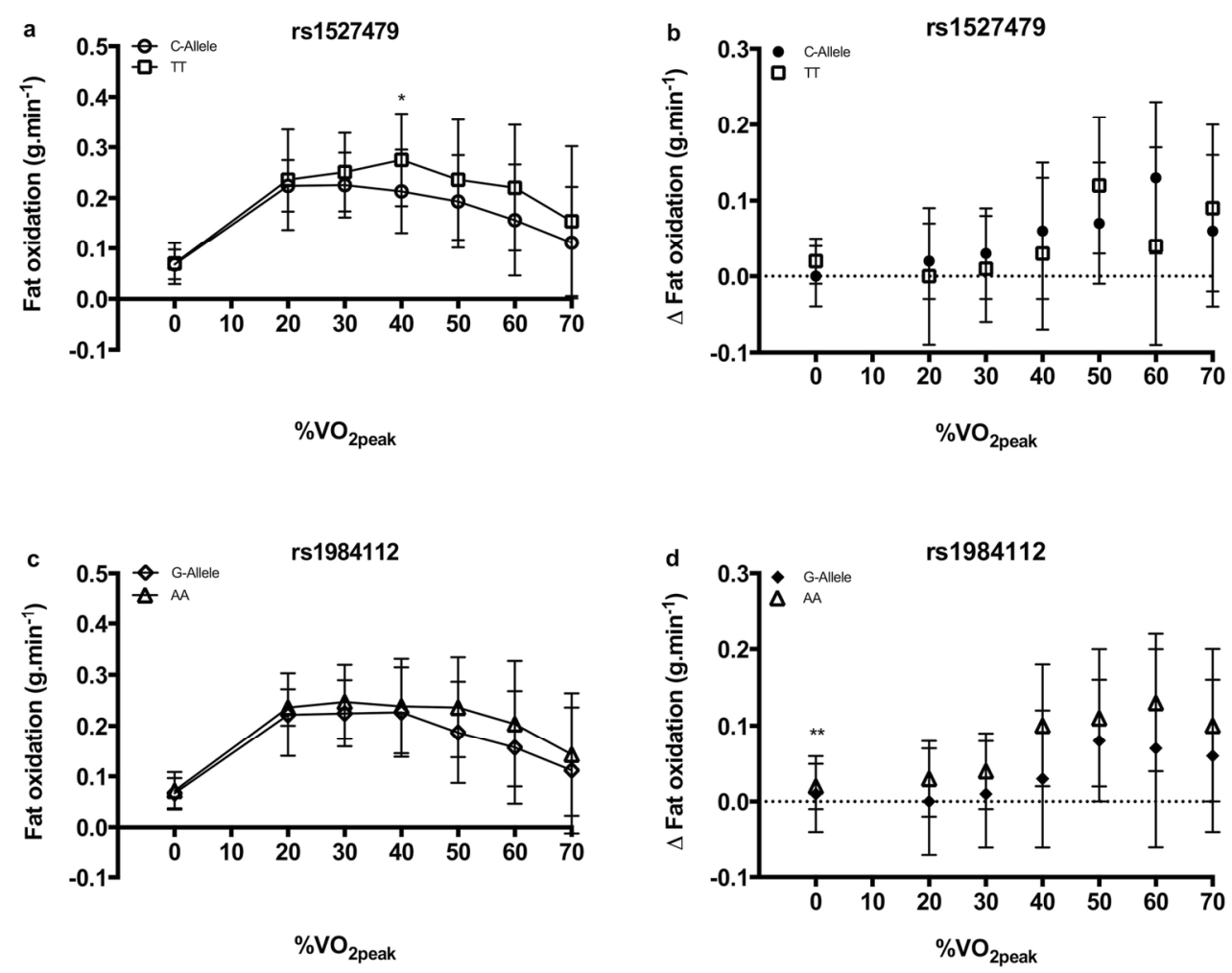

$144 \times 114 \mathrm{~mm}(300 \times 300$ DPI $)$ 

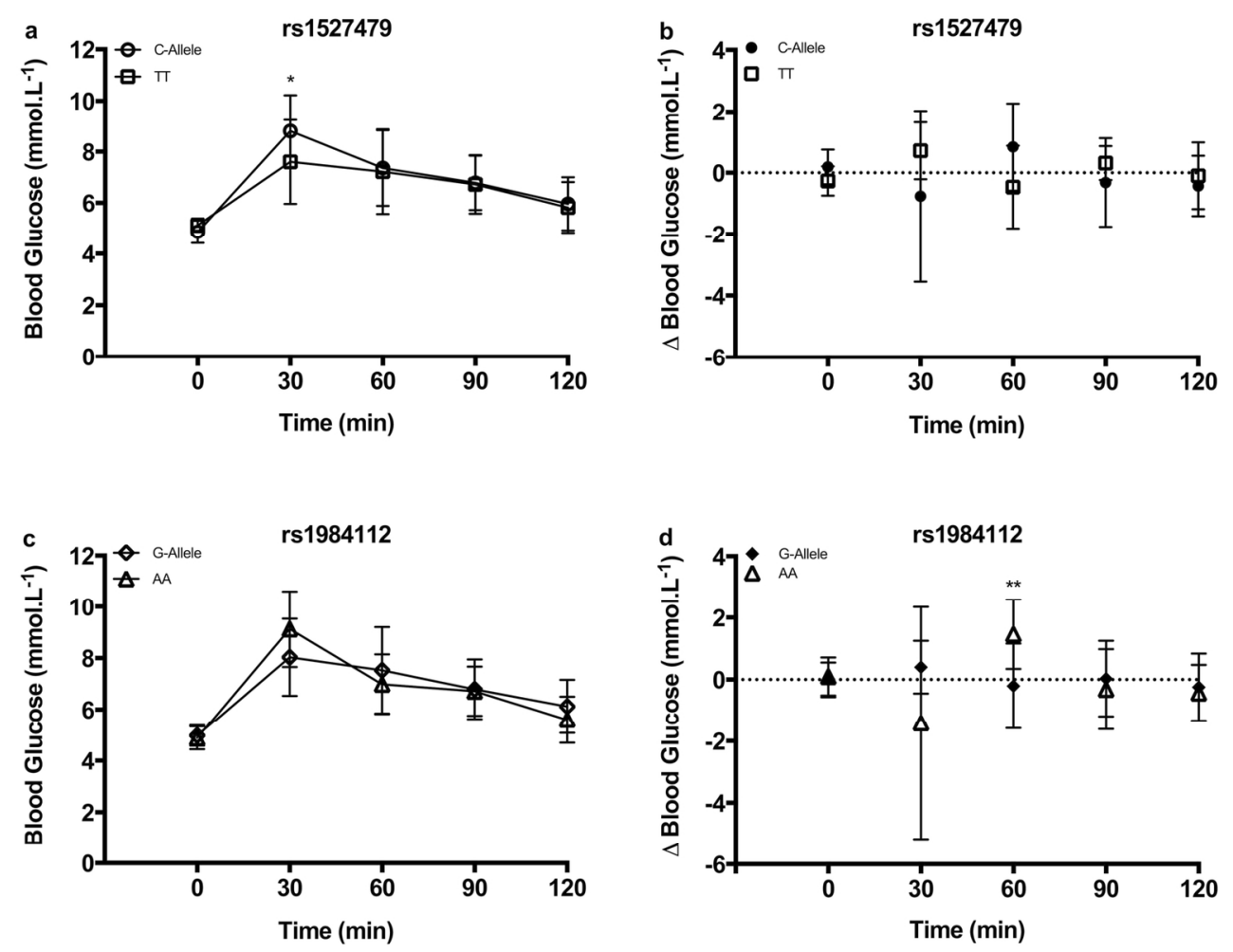

$143 \times 112 \mathrm{~mm}(300 \times 300 \mathrm{DPI})$ 